\title{
Field and laboratory investigation of rainfall-triggered slope failure in unsaturated loess soils, New Zealand
}

\author{
Katherine Yates ${ }^{1},{ }^{*}$, Adrian Russell ${ }^{2}$, and Clark Fenton $1^{1}$ \\ ${ }^{1}$ Department of Geological Sciences, University of Canterbury, New Zealand \\ ${ }^{2}$ Department of Civil and Environmental Engineering, University of New South Wales, Australia
}

\begin{abstract}
Shallow rainfall triggered slope failures occur frequently in loess and loess-derived deposits across the South Island, New Zealand. These failures, which occur in both natural slopes and engineered cuttings, impact road infrastructure, residential housing and rural land use. When dry, the loess can form near vertical cuttings. However, with increase in moisture content loess slopes become susceptible to shallow slope failures. To date, the influence of negative pore-water pressure (suction) on the stability of loess slopes in New Zealand has not been well understood. In this paper, data from long term in situ field monitoring of rainfall, suction and volumetric water content from a loess slope in Banks Peninsula, Canterbury are presented with laboratory triaxial test results undertaken on undisturbed unsaturated loess samples. Field and laboratory soil responses to wetting and drying are compared, and the characteristics of rainfall events which reduce suction in situ and therefore slope stability are discussed.
\end{abstract}

\section{Introduction}

Loess and loess-derived soils (e.g., loess colluvium) are widespread across slopes in Canterbury, in the South Island of New Zealand (Fig. 1). These Late Pleistocene and Postglacial (Holocene) age deposits were formed by aeolian processes and are primarily composed of siltsized grains [1-4]. In general, these loess deposits are unsaturated and are sensitive to changes in moisture content. At low moisture contents $(\sim 5 \%)$ cut slopes in loess can stand near-vertical, however, the shear strength decreases rapidly upon relatively small (2\% - 3\%) increases in moisture content $[5,6]$. This, along with susceptibility of the loess to dispersion, makes the material prone to instability upon infiltration of rainfall.

Typical mechanisms of slope failure include shallow slides, debris flow and tunnel gullying (internal erosion) $[1,2,7]$. Because these materials are widespread in Canterbury, instability can be problematic for residential development, infrastructure and rural land use. In particular, the popular tourist area of Akaroa Harbour on Banks Peninsula (Fig. 1) has frequent instability issues due to a higher average annual rainfall than the surrounding Canterbury Plains. Previous research on Canterbury loess has provided limited review of the behaviour of the material as an unsaturated soil [6].

The purpose of this paper is to provide an overview of current research into the unsaturated characteristics of loess from Akaroa Harbour, Canterbury. This research includes triaxial testing and laboratory characterisation of the soil-water characteristics of Canterbury loess. Data from long-term field instrumentation of a natural loess slope is presented alongside laboratory data to examine the hydraulic state of loess in situ. Preliminary findings of this ongoing research programme are presented.

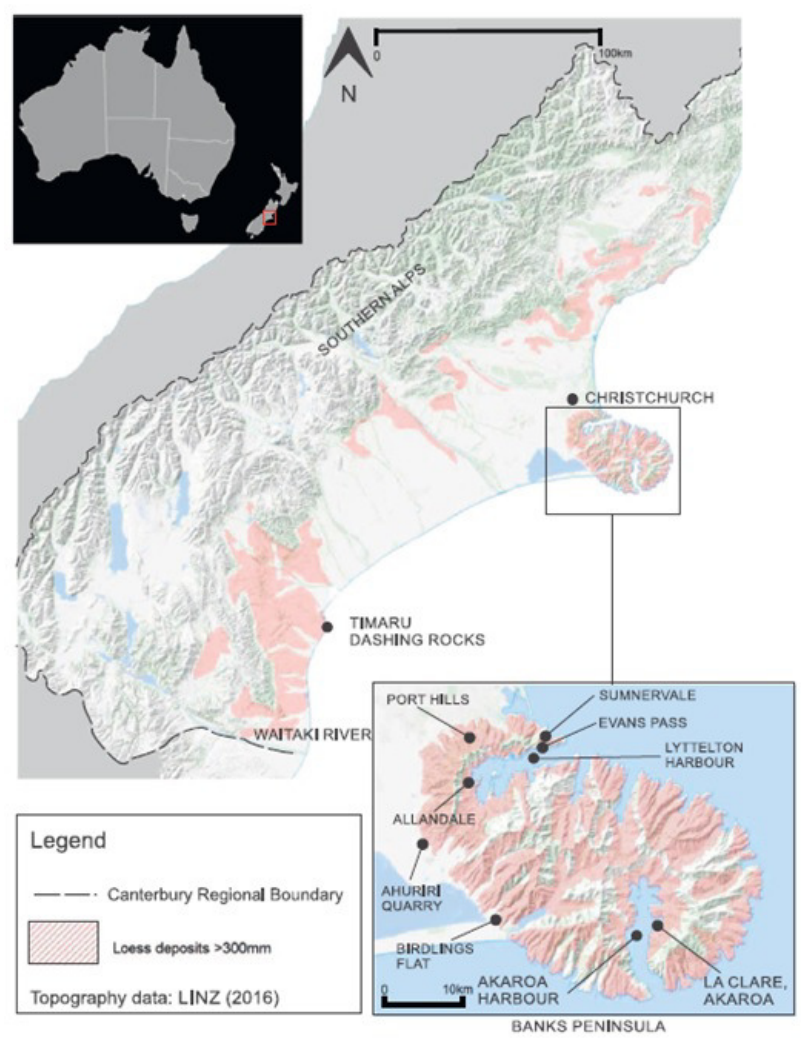

Fig. 1. Distribution of loess across Canterbury, New Zealand [6]. 


\section{Laboratory testing of Akaroa Loess}

\subsection{Index properties}

Akaroa loess is classified as low plasticity clay according to the Unified Soil Classification system. Index properties are listed in Table 1, and the particle size distribution curve is shown in Figure 2.

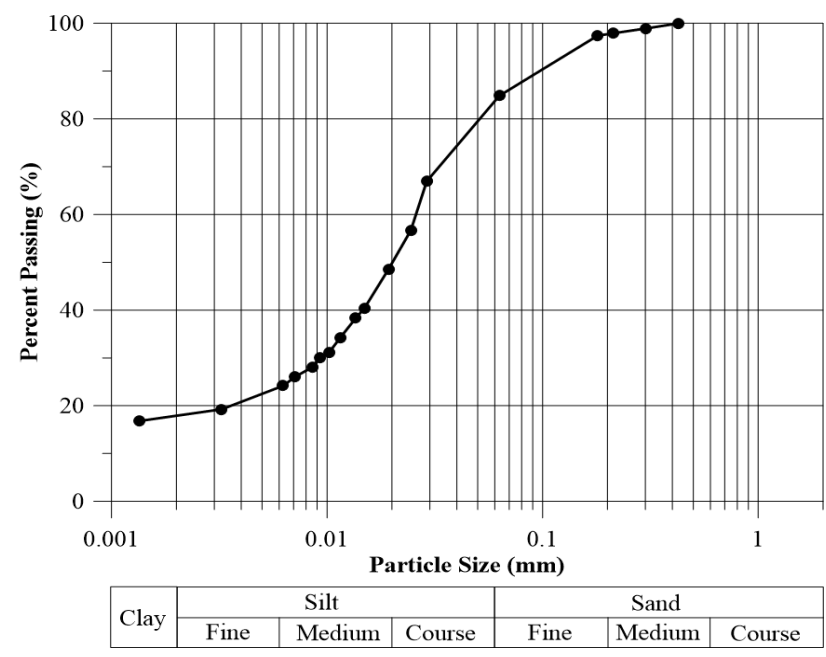

Fig. 2. Particle size distribution curve for Akaroa Loess.

Table 1. Index properties of Akaroa Loess.

\begin{tabular}{|c|c|}
\hline Property & Value \\
\hline Dry Density $\left(\mathrm{g} / \mathrm{cm}^{3}\right)$ & 1.6 \\
\hline Liquid Limit (\%) & 24.8 \\
\hline Plastic Limit (\%) & 17.2 \\
\hline Plasticity Index & 7.6 \\
\hline Specific Gravity & 2.78 \\
\hline Gravel Content (\%) & 0 \\
\hline Sand content (\%) & 16.0 \\
\hline Fines content (\%) & 84.0 \\
\hline Clay fraction (\%) & 19.3 \\
\hline Unified Soil Classification & CL \\
\hline
\end{tabular}

\subsection{Triaxial testing}

A series of isotropically-consolidated, drained triaxial tests were conducted on saturated and unsaturated intact loess specimen. A modified Bishop Wesley device was used for both saturated and unsaturated triaxial testing. Intact specimens were hand-carved from block samples extracted from a road cutting near the field instrumentation site in Akaroa Harbour. Block samples were extracted from the site using hand tools and then shaped with a hand saw and fine sand paper to $50 \mathrm{~mm}$ diameter and $100 \mathrm{~mm}$ height.

All specimens were sheared at a strain rate of 0.004 $\mathrm{mm} / \mathrm{min}$ to allow dissipation of pore pressures during shearing. The selected strain rate was determined from consolidation testing of saturated intact and remoulded specimens.

Fig. 3 presents shear strength data for saturated and unsaturated samples. Suction values for unsaturated specimens were $200 \mathrm{kPa}$ and $125 \mathrm{MPa}$ (at natural moisture content of $3 \%$ ). $200 \mathrm{kPa}$ suction was applied to specimen post-saturation using the axis translation technique and a High Air Entry porous disk (1500 kPa capacity). Unsaturated specimens were sheared under constant suction.

Specimen at natural moisture content were sheared without pre-test saturation or application of suction. Suction in the specimen was measured to be $125 \mathrm{MPa}$ prior to the test. The purpose of testing at natural moisture content was to examine the deformation behavior of the loess found in situ at low moisture contents and high suction values. Confining pressures for specimen where suction was $125 \mathrm{Mpa}$ were required to be lower than that for specimen where suction was 200 $\mathrm{kPa}$ due to limitations to the axial load transducer in the triaxial.

Triaxial test results (Fig. 3) indicate an increase in shear strength of the soil relative to increase in suction. When suction is $125 \mathrm{MPa}$ failure was brittle, and similar to failure of soft rock. Less than $6 \%$ volumetric compression was recorded for each test.

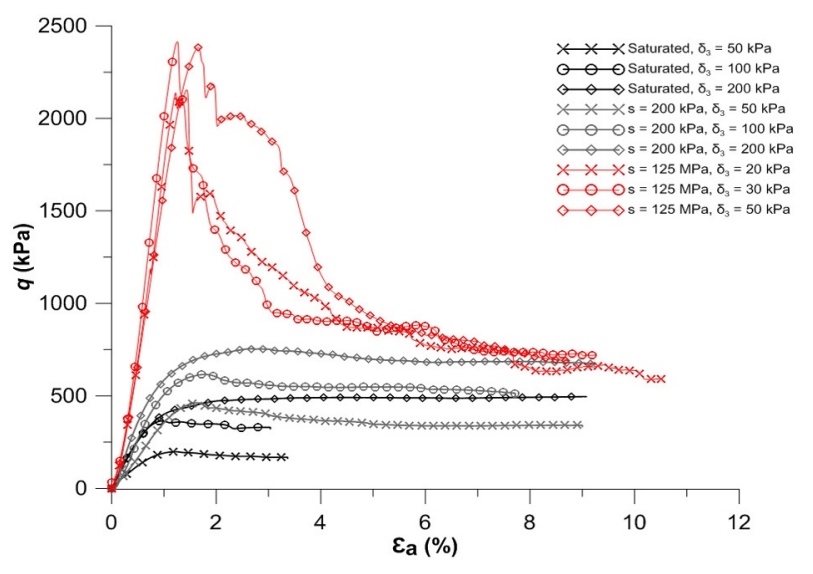

Fig. 3. Deviator stress $(q)$ vs. axial strain $\left(\varepsilon_{\mathrm{a}}\right)$ from triaxial testing on intact Akaroa Loess.

\subsection{Soil-water characteristic curve}

The soil water characteristic curve (SWCC) of the loess was determined using the pressure plate test (ASTM D6836-16) and the WP4C soil potential (dew point) apparatus. Remoulded samples of loess were prepared for both test methods by tamping moisten material to a dry density of approximately $1.6 \mathrm{t} / \mathrm{m}^{3}(\mathrm{e}=0.69)$ to represent densities observed at the field instrumentation site.

Remoulded specimen prepared for the pressure plate test were saturated by soaking in a de-aired water overnight prior to commencing the test. Two High Air Entry plates $(300 \mathrm{kPa}$ and $1500 \mathrm{kPa}$ air entry value) were used to obtain a wide range of suction values. Prior to 
commencing the test, the dimensions of each specimen were recorded to allow observation of volumetric change with changes in suction. Two remoulded samples were removed at each pressure stage for destructive testing.

A WP4C device (Decagon Devices Ltd) was used to determine the soil water characteristic curve for suctions above $1379 \mathrm{kPa}$. The apparatus uses a chilled-mirror to measure total suction within the sample. Immediately after suction is measured, the sample is measured for volumetric change and then dried to determine the moisture content. For these tests, osmotic suction was assumed to be negligible.

Because the loess soil in Akaroa has a fractal particle size distribution, a SWCC relationship can be clearly established by presenting both pressure plate and dew point test results in $\log (\mathrm{Sr})-\log (\mathrm{s})$ plane (Figure 4) [8, 9]. Results from both laboratory test methods correlate well across the range of suctions tested. The main drying curve and top scanning line are identified from Fig. 4. The slope of the top scanning line is a representation of the slope of other scanning lines down the SWCC.

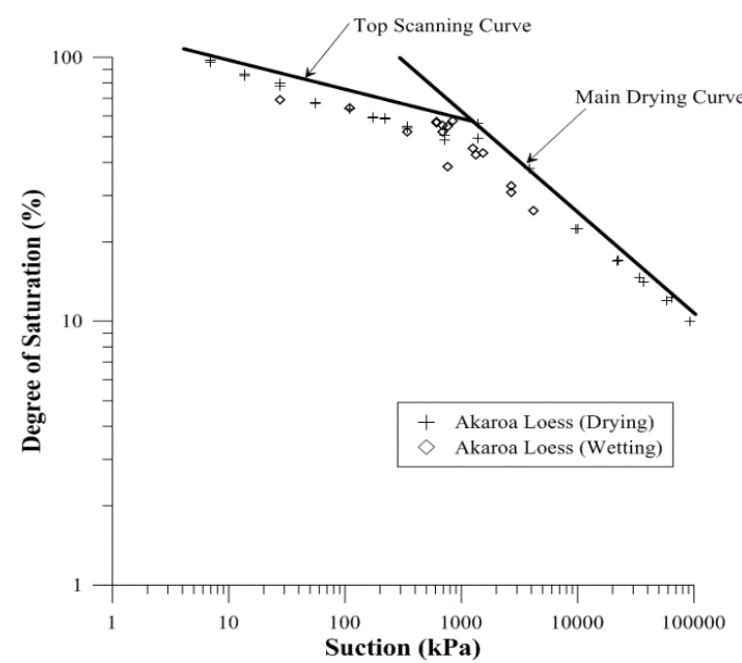

Fig. 4. $\log (\mathrm{s})$ vs. $\log (\mathrm{Sr})$ plot of laboratory testing data for SWCC for remoulded Akaroa loess where $\mathrm{e}=0.69$, including interpretation of main drying and top scanning curve.

\section{Field Instrumentation}

To examine the unsaturated behaviour of loess in situ, a field instrumentation programme was conducted in a natural loess slope in Akaroa Harbour. The monitoring system was installed for an 18-month period to measure matric suction, volumetric water content and rainfall. The site selected for instrumentation is a grassed, northfacing $15^{\circ}$ slope adjacent to a historic gully erosion feature (downslope) and recent shallow instability (upslope hummocky ground).

Volumetric water content (VWC) was measured using 12 Campbell Scientific CS616 water content reflectometers. These were calibrated in the laboratory prior to deployment. Matric suction was measured indirectly using 12 Decagon MPS-6 devices which were calibrated by the manufacturer for drying only. These devices were chosen for their durability for long-term installation and lack of required ongoing maintenance. A TB3 tipping bucket rain gauge from Hydrological Services Pty Ltd was installed at ground surface to measure local precipitation. All instrumentation, including the data logger (Campbell Scientific CR1000) were powered by solar panel and one rechargeable deep cycle battery.

Each CS616 sensors were installed in direct contact with the in situ soil at the base of individual machine augured holes. A similar installation method was applied to the MPS-6 sensors however each sensor was encased in saturated remoulded loess prior to lowering down the auger hole. This was undertaken to ensure good contact between the sensor and soil. Holes were backfilled with compacted soil extracted from the site. Probes were arranged in four arrays comprised of three MPS-6 sensors and three CS616 sensors. MPS-6 and CS616 sensors were installed in pairs at approximately $0.5 \mathrm{~m}$, $1.0 \mathrm{~m}$ and $2.0 \mathrm{~m}$ deep to observe the wetting front through the soil (Fig. 5, Fig. 6). The probes were installed in October 2017 and removed in May 2019.

A selection of the monitoring data is presented in Fig. 7 and 8. This shows the hydrological response recorded onsite over January and February 2018 (Austral Summer). This section of data is presented because it provides an example of the loess in situ undergoing prolonged periods of drying in between two rainfall (wetting) events. Suction measurements reached the highest $(\sim 5 \mathrm{MPa})$ during these months, and correspondingly the VWC the lowest $(\sim 11 \%)$.

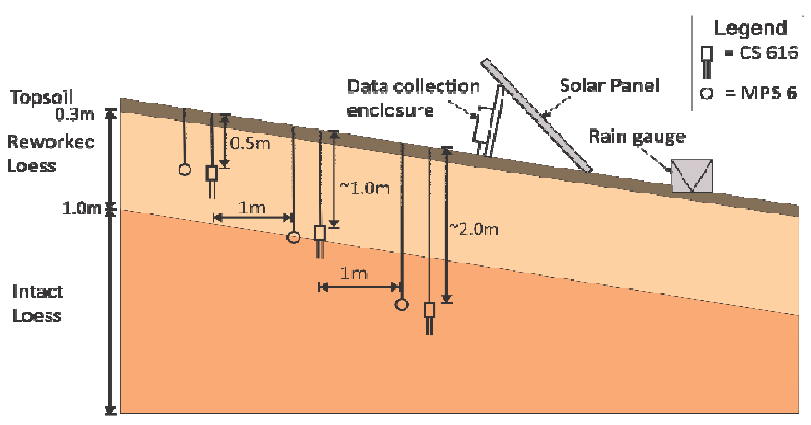

Fig. 5. Cross section schematic of one array of probes installed on site.

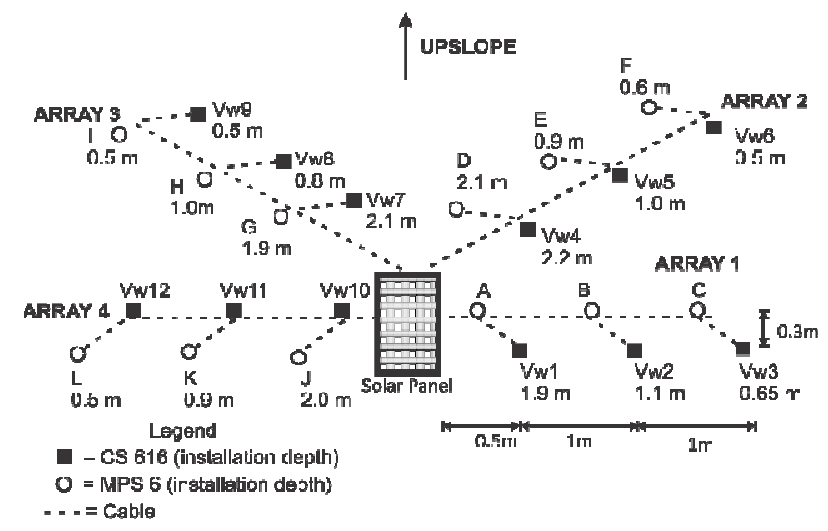

Fig. 6. Plan view schematic of probe installation including four arrays and solar panel. 
a)

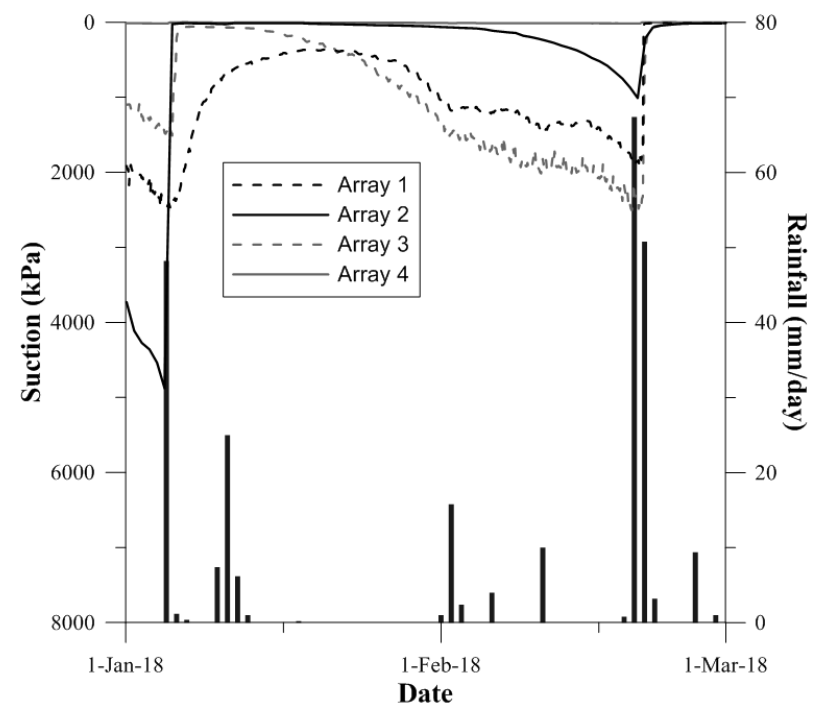

b)

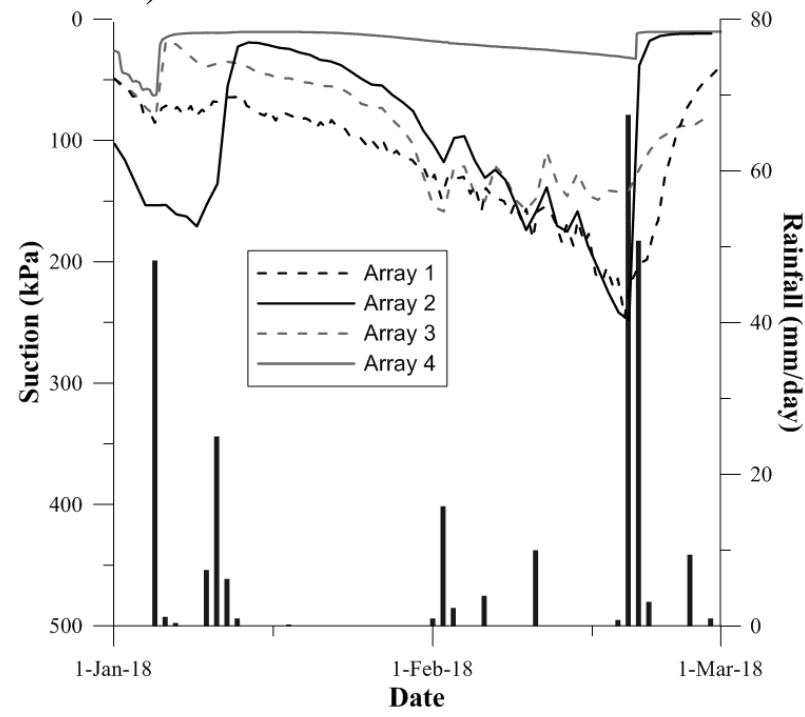

c)

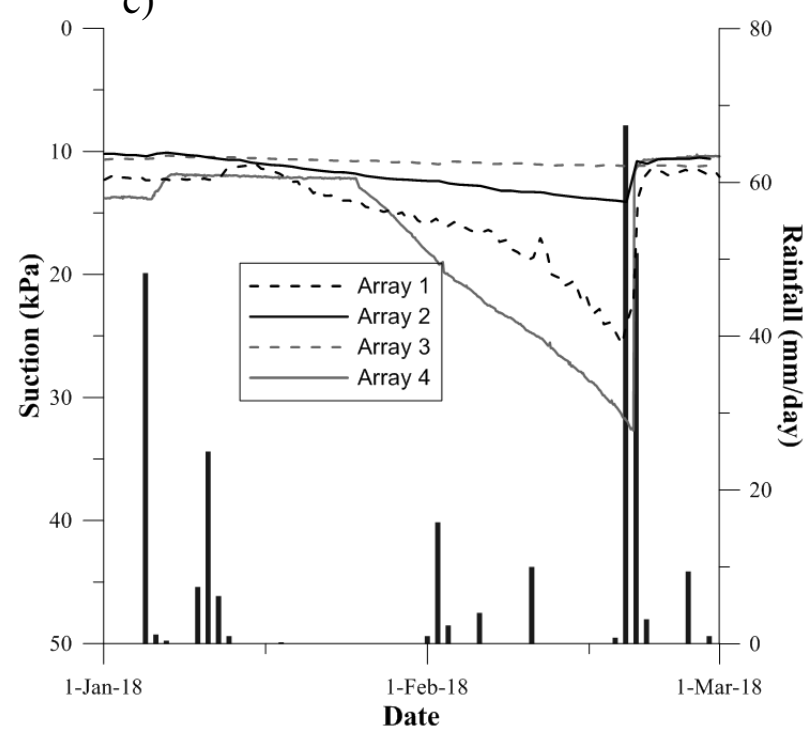

Fig. 7. Suction measurements between 1 January 2018 to 28 February 2018 from monitoring site in Akaroa Harbour. (a) $0.5 \mathrm{~m}$ depth, (b) $1.0 \mathrm{~m}$ depth, (c) $2.0 \mathrm{~m}$ depth. a)

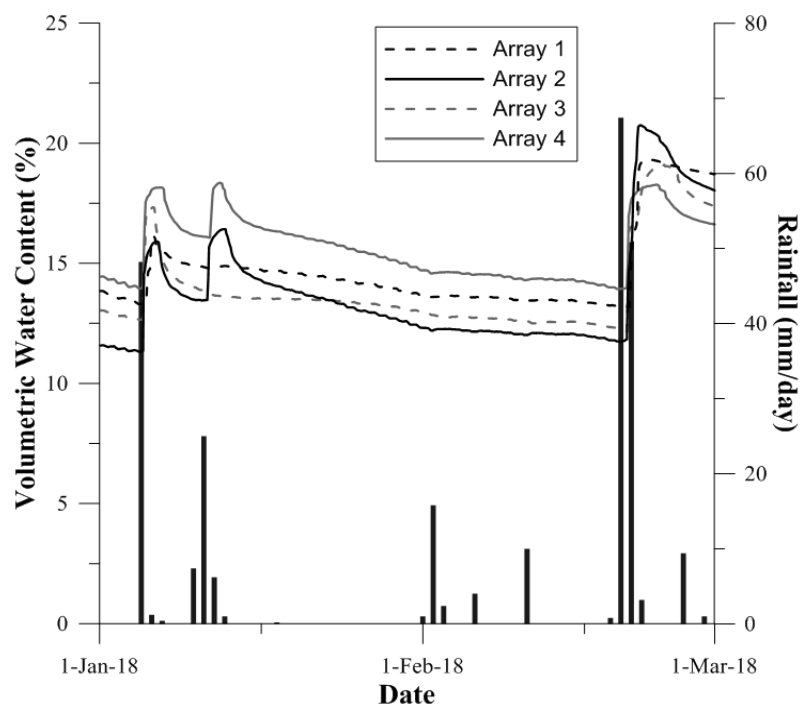

b)

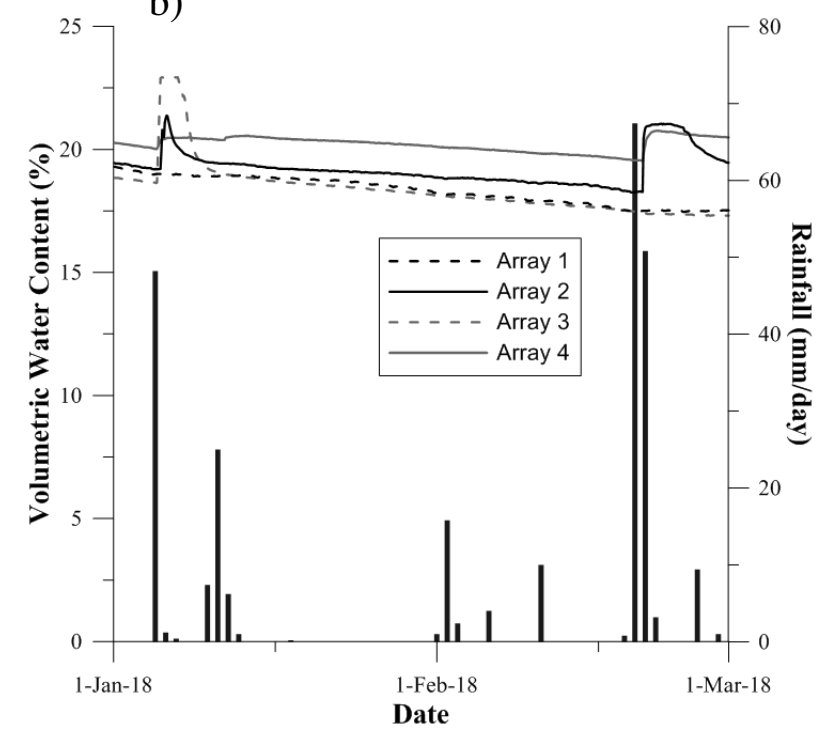

c)

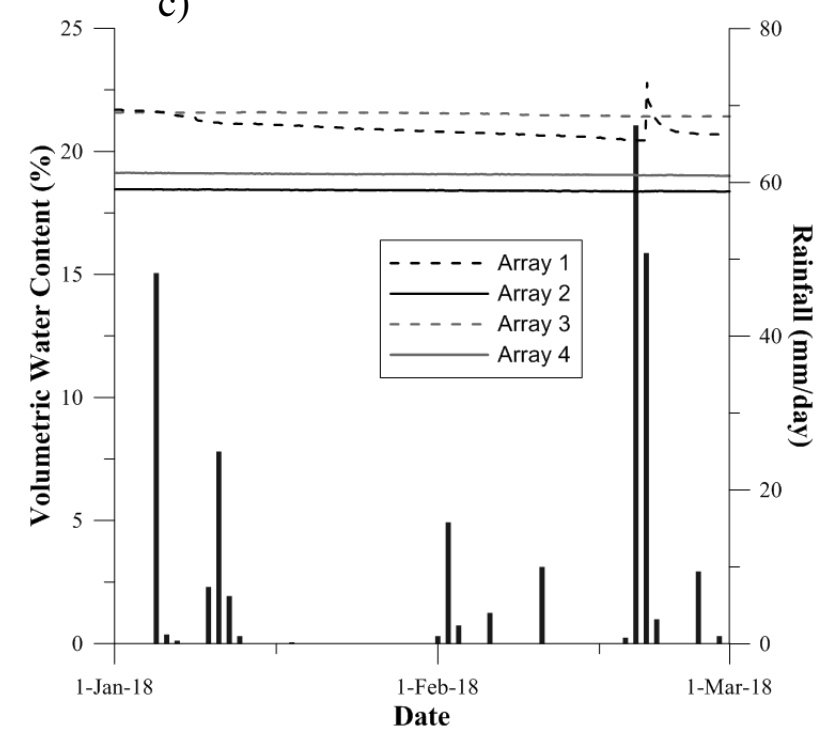

Fig. 8. Volumetric water content measurements between 1 January 2018 to 28 February 2018 from monitoring site in Akaroa Harbour. (a) $0.5 \mathrm{~m}$ depth, (b) $1.0 \mathrm{~m}$ depth, (c) $2.0 \mathrm{~m}$ depth. 
Climatic processes, including evapotranspiration, air humidity and temperature, are attributed to the drying of the loess over this time. Although general wetting and drying trends are comparative between CS616 and MPS6 sensors, there is some discrepancy in between the data sets that may be attributed to localized variation in exposure to hydraulic processes. Some fluctuation in the MPS-6 data at $0.5-1.0 \mathrm{~m}$ depths is due to intermittent interference recorded on site.

Two major rainfall events occurred on 5 January 2018 and 20 February 2018 (ex-tropical cyclone Gita) caused significant reduction in suction to $<50 \mathrm{kPa}$ and correspondently VWC increased to $18 \%-21 \%$. Characteristics of these rainfall events are detailed in Table 2. Changes to the hydraulic state of the deeper loess $(>1.0 \mathrm{~m})$ was less pronounced than that recorded by the shallower probes $(\sim 0.5 \mathrm{~m})$ due to less exposure to meteorological influences. Several minor rainfall events occurred during this period, however these did not result in a change in the hydraulic path of the material. Between 1 January to 28 February 2018 the loess on site remained in an unsaturated state up to $2 \mathrm{~m}$ depth despite infiltration from recorded rainfall events.

Table 2. Characteristics of major rainfall events.

\begin{tabular}{|c|c|c|}
\hline Property & $\begin{array}{c}\text { 5 January } \\
2018\end{array}$ & $\begin{array}{c}\text { 20 February 2018 } \\
\text { (ex-cyclone Gita) }\end{array}$ \\
\hline Duration (hrs) & 21 & 35.3 \\
\hline $\begin{array}{c}\text { Max. Intensity } \\
(\mathrm{mm} / \mathrm{hr})\end{array}$ & 14.4 & 9.6 \\
\hline Total rainfall $(\mathrm{mm})$ & 48.2 & 118.2 \\
\hline
\end{tabular}

\section{Comparison between laboratory and field data}

In situ field monitoring of a loess slope and laboratory testing of the SWCC for Akaroa loess can be used to examine the unsaturated behaviour of the material. Drying data recorded between 1 January 2018 and 28 February 2018 from field instrumentation is presented with laboratory SWCC to examine the hydraulic behaviour of in situ loess (Fig. 9). Wetting data was not included due to the lack of reliability in the MPS-6 measurements. Comparison between the data sets indicate that the hydraulic state of the loess remained on one of the scanning lines during periods of drying and never reached the main drying curve of the SWCC.

To examine agreement between the laboratory scanning line and the field scanning line, the slope of the top scanning line is replicated nearer to the field data. As the depth $(\mathrm{m})$ of the recorded field data increases, the hydraulic state of the loess is positioned towards the 'wetter end' of the scanning line. With depth, agreement between the slope of the scanning line and the field data also increases. Localised variation in particle size distribution and density of the soil $<0.5 \mathrm{~m}$ may lead to variation in the scanning line slope observed on site.
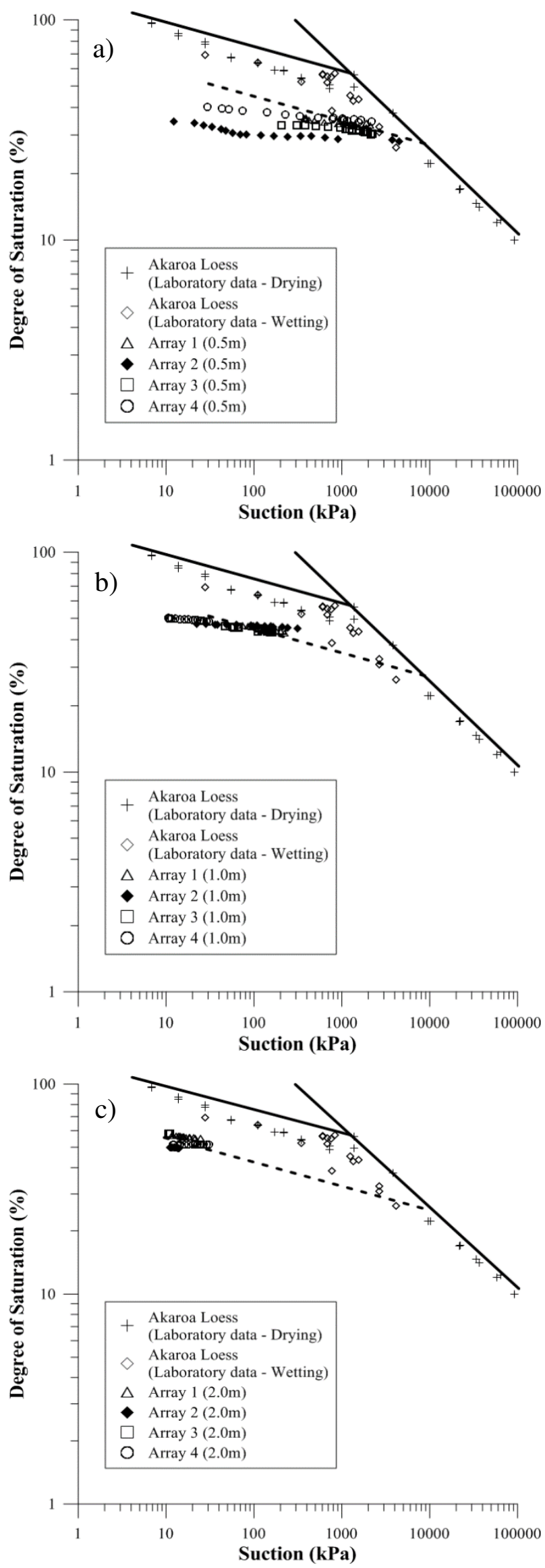

Fig. 9. Overlay of field monitoring data on laboratory testing data, (a) $0.5 \mathrm{~m}$ deep probes, (b) $1.0 \mathrm{~m}$ deep probes, (c) $2.0 \mathrm{~m}$ deep probes. 
Noticeably, the wetter field data located on the scanning curve does not appear to reach the main wetting curve. Possible reasons for this may be that the main wetting curve is located at a different location to that of what is implied from the laboratory test data. Alternatively, the hydraulic state of loess in situ may remain on a scanning curve when exposed to continuing climatic changes. Further work is required to understand this behaviour.

Typical modes of shallow instability in the loess can be explained by examining both field and monitoring data. It was observed from the field monitoring data that the largest variation in the hydraulic state of the loess was within the upper $\sim 1.0 \mathrm{~m}$. More importantly, this upper layer underwent the greatest reduction in suction upon rainfall infiltration. As it is shown the shear strength of the loess decreases with decrease in suction, shallow failure mechanisms $(<1 \mathrm{~m})$ can be expected.

\section{Conclusions}

Field instrumentation and laboratory testing has been conducted to examine the unsaturated characteristics of loess in New Zealand. This paper examines some of the data collected during this study. As expected, triaxial testing on saturated and unsaturated specimen indicate an increase in shear strength with increase in suction. Due to an observed reduction in suction that occurs upon infiltration of rainfall, it is expected that the stability of the loess will reduce particularly in the upper $0.5 \mathrm{~m}$ of the loess profile. Research is ongoing to further quantify the effect of suction on loess slope stability.

Comparison between laboratory data and drying data from field instrumentation showed that the hydraulic state of the loess during January and February 2018 remained on one of the scanning lines. The main drying and wetting lines were not reached during this period. Good agreement was observed between the slope of the laboratory scanning line and the slope of the field scanning line.

\section{Acknowledgements}

The authors acknowledge the contribution of Environment Canterbury (ECan) and University of Lincoln to this research.

\section{References}

1. Bell, D.H., P.J. Glassey, and M.D. Yetton. Chemical stabilisation of dispersive loessical soils, Banks Peninsula, Canterbury, New Zealand. in 5th International IAEG Congress. 1986. Buenos Aires, Argentina.

2. Bell, D.H. and B.B. Trangmar. Regolith materials and erosion processes on the Port Hills, Christchurch, New Zealand. in 5th International Conference and Field workshop on Landslides. 1987. Christchurch, New Zealand.

3. Raeside, J.D., Loess Deposits of the South Island, New Zealand, and Soils Formed on them. New
Zealand Journal of Geology and Geophysics, 1964. 7(January 2015): p. 811-838.

4. Ives, D., Nature and distribution of loess in Canterbury, New Zealand. New Zealand Journal of Geology and Geophysics, 1973. 16(3): p. 587-610.

5. Hughes, T.J., A Detailed Study of Banks Peninsula Shear Strength. 2002.

6. Yates, K., C.H. Fenton, and D.H. Bell, A review of the geotechnical characteristics of loess and loessderived soils from Canterbury, South Island, New Zealand. Engineering Geology, 2018. 236: p. 11-21.

7. Hutchinson, G., Akaroa Harbour suffers extensive earth movements. Soil \& Water, 1975. 12: p. 6-7.

8. Russell, A.R., How water retention in fractal soils depends on particle and pore sizes, shapes, volumes and surface areas. Géotechnique, 2014. 64(5): p. 379-390.

9. Russell, A.R. and O. Buzzi, A fractal basis for soilwater characteristics curves with hydraulic hysteresis (Technical Note). Géotechnique, 2012. 62(3): p. 269-274. 